\title{
A qualitative study of the work environment in obstetrical nursing in northeastern Ontario, Canada
}

\author{
Behdin Nowrouzi ${ }^{* 1}$, Nancy Lightfoot ${ }^{2}$, Lorraine Carter ${ }^{3}$, Michel Larivère ${ }^{4}$, Ellen Rukholm ${ }^{5}$, Diane Belanger-Gardner ${ }^{6}$ \\ ${ }^{1}$ Centre for Research in Occupational Safety and Health, Laurentian University, Sudbury, ON, Canada \\ ${ }^{2}$ Schools of Rural and Northern Health, Social Work, and Human Sciences Division, Northern Ontario School of Medicine, \\ Laurentian University, Sudbury, ON, Canada \\ ${ }^{3}$ School of Nursing, Nipissing University, North Bay, ON, Canada \\ ${ }^{4}$ School of Human Kinetics and Northern Ontario School of Medicine, Laurentian University, Sudbury, ON, Canada \\ ${ }^{5}$ Centre for Rural and Northern and Health Research, Laurentian University, Sudbury, ON, Canada \\ ${ }^{6}$ Health Sciences North, Sudbury, ON, Canada
}

Received: February 28, 2015

DOI: $10.5430 /$ jnep.v5n $7 \mathrm{p} 10$
Accepted: April 12, $2015 \quad$ Online Published: April 16, 2015

URL: http://dx.doi.org/10.5430/jnep.v5n7p10

\begin{abstract}
Background: Nurses work environment is inherent with stressors that impact their quality of work life (QWL). Moreover, there is a dearth of evidence examining occupational stressors and QWL in nurses working in northern and rural areas of Canada. Objective: The purpose of this qualitative study was to explore and understand the work environment of registered nurses working in obstetrics at four hospitals in northeastern Ontario, Canada.

Methods: This qualitative study used thematic analytic approach to describe the work environment of nurses as it pertained to their occupational stress and QWL. During the analysis, themes and subthemes emerged relating to their underlying factors that influenced the nurses' work environment and QWL.

Results: Five key themes that emerged from the semi-structured qualitative interviews were: workplace stress, relationships with colleagues (in and out of the workplace), quality of work life of obstetrical nurses, changes in care delivery and model of care (cross-training) and limited resources in the workplace. The nurses discussed both the positive aspects and challenges of their work environment.

Conclusions: The study focuses the importance of understanding the work environment of nurses and its relationship to work stress, QWL and location of cross-training. Ameliorating nurses work environments is crucial to fostering better client care and bolstering recruitment and retention strategies, especially in rural and northern regions.
\end{abstract}

Key Words: Nurses, Quality of work life, Occupational stress, Work environment, Rural, Northern, Qualitative

\section{INTRODUCTION}

The work environment of nurses is stressful ${ }^{[1]}$ with specific physical and psychosocial stressors. ${ }^{[2]}$ In Canada, the 2005 National Survey of the Work and Health of Nurses reported absenteeism due to illness and injury for nurse supervisors and registered nurses to be 1.7 million hours in $2005 .{ }^{[3]}$ This number of hours is the equivalent of 9,754 full-time nursing jobs. ${ }^{[3]}$ Although absenteeism has been related to stress and identified as an issue in all kinds of nursing, obstetrical nursing is an especially stressful area of nursing due to long and Canada. 
unpredictable work hours and disruptions to nurses' personal time. ${ }^{[4]}$ In other instances, caring for and supporting parents whose infant has died is demanding, difficult, and stressful. ${ }^{[5]}$ Obstetrical nurses may experience a sense of personal failure as the following statement suggests, "I feel helpless because I can really only listen and be there to help. . I cannot lessen this devastating loss". ${ }^{[6]}$

Improving patient care quality and health services delivery include approaches that improve nurses work environment. ${ }^{[7]}$ Examining nurses' work environment (e.g., setting where nurses work) and ways to retain and recruit new workers is critical. This is because the workforce in Canada will need an additional 60,000 full-time equivalent RNs by $2022 .^{[8]}$ while there it is 250,000 in the United States over the next 15 years. ${ }^{[9]}$

Given the time and energy workers spend at work, it is important that work be a place where workers are generally satisfied and happy. ${ }^{[10]}$ Additionally, work affects not only the employee's physical but also his or her psychological well-being and general quality of work life (QWL). ${ }^{[1]}$ A high QWL has been reported to attract new employees and retain a workforce ${ }^{[12]}$ and studies have identified factors that contribute to nurses' QWL. ${ }^{[13,14]}$ Thus, employers and occupational health experts need to understand the components that comprise a healthy work experience. Moreover, location of cross-training has been associated with increased clinical competencies among nurses in order to work in all work environments of obstetrics and allow for greater decision-making capacity in the delivery of health services. ${ }^{[14]}$ In this inquiry, a cross-trained nurse in obstetrics is a nurse who is able to perform the job tasks and responsibilities of the three areas of the obstetrical unit including labor, delivery, recovery, and postpartum.

QWL affects not only job satisfaction, but also satisfaction in other life domains including: leisure, family, financial well-being, health, housing, friendships, education attainment, community engagement, neighborhood interactions, spiritual well-being, the environment, and cultural and social status. ${ }^{[15]}$ Furthermore, the association between work, non-work life domains, and work-related stress ${ }^{[16]}$ is also a factor in QWL. ${ }^{[17]}$ Evidence has demonstrated that a negative quality of work-life situation is related to lack of work-life balance. ${ }^{[17-19]}$

For the purposes of this study, quality of work life was defined according to question 24 of the Work-Related Quality of Life Scale: "I am satisfied with the overall quality of my working life." Evidence has shown that a negative quality of work life situation is related to lack of work-life balance. ${ }^{[17,20,21]}$ Participants were provided with this definition during the interview.

In northern and rural settings such as northern Ontario, Canada, positive work environments are essential to the recruitment and retention of health care professionals. Given the enticements of larger settings in southern locations such as a superior quality of life (e.g., increased likelihood of employment, more employment choices, greater access to social and entertainment opportunities, etc.), it is necessary for the northern part of the province to take deliberate steps to ensure it has the health professionals it needs. Additionally, studies have shown that strong, positive QWL within health care organizations can contribute to other positive outcomes including workers' physical and psychological health and enhanced health services delivery. ${ }^{[19,22]}$

Aims

The purpose of this qualitative study was to explore and understand the work environment of registered nurses working in obstetrics at four hospitals in northeastern Ontario, Canada.

\section{Methods}

\subsection{Design}

This study was part of a larger project examining the quality of work life and occupational stressors among obstetrical nurses working in urban northeastern Ontario, Canada. The two-part study used a mixed-method sequential explanatory. ${ }^{[23]}$ Data were generated in two ways: through questionnaires completed by registered nurses working in working in the labor, delivery, and post-partum areas of selected northeastern Ontario cities (quantitative component), and through semi-structured interviews with a select number of nurses (qualitative component).

\subsection{Sample and setting}

Nurses from the four participating hospitals were invited to take part in the study. Recruitment of participants for the semi-structured interviews occurred through placing an advertisement on the bulletin board in each unit. In addition, in the final question of the questionnaire (phase I), interested respondents were invited to provide their e-mail address so they could be contacted about a follow-up interview. These individuals were contacted by email about the possibility of participating in an interview. A follow-up phone call was made to those interested to provide them with details about the study and setup a time to complete the interview.

In total, 111 nurses completed the quantitative questionnaire ( $80.4 \%$ response rate) either online or in paper format. The quality of data was identical for the paper and online versions of the questionnaire. The majority of participants were 
women $(94.6 \%)$ ranging in age from 24 to 64 years (Mean $=41.9$, S.D. $=10.2)$. The mean age of respondents at Heath Sciences North (Sudbury) was 41.6 (S.D. $=9.5$ ) years, 44.1 (S.D. = 8.64) years at Timmins and District Hospital, 41.2 years (S.D. $=11.3$ ) at Sault Area Hospital and 40.6 years $($ S.D. $=11.9)$ at North Bay Health Centre. Forty-six percent of respondents worked at Health Sciences North; $19.8 \%$ worked at North Bay Regional Health Centre; $18.0 \%$ worked at Sault Area Hospital; and 16.2\% at Timmins and District Hospital. The nurses had, on average, 16.3 years (S.D. = 10.8) of nursing experience and 11.6 years (S.D. $=9.01$ ) of experience working in obstetrics. Sixty-three percent of respondents worked full-time, $33 \%$ worked part-time, and $4.5 \%$ were casual workers.

\subsection{Data collection}

Six one-hour interviews were conducted with nurses from the Health Sciences North $(\mathrm{n}=2)$, North Bay Regional Health Centre $(n=2)$, and Sault Area Hospital in person $(n=2)$. The duration of each interview was one hour in length, and there was flexibility in the ordering of questions of the interview guide in order to facilitate rapport with the participants.

Five of the interviews were conducted by phone and one was completed face-to-face in Sudbury, Ontario, Canada. At one of the four hospitals (Health Sciences North), the nurses were cross-trained to work in all aspects of obstetrical care (crosstrained), while, at the other locations, the nurses worked in one specific area of obstetric care (non-cross-trained). All participants were interviewed in a place convenient to them. The setting selected was conducive to participant's comfort during the interviewing process which were audio recorded. All interviews were completed between July and September, 2012. The primary author completed all the interviews.

\section{Interview guide}

A semi-structured interview guide was developed with the help of clinical and academic advisors. Specifically, we sought the assistance of a pediatric clinical nurse specialist, administrative director of the birthing unit at Health Sciences North, and nursing faculty at Laurentian University. Themes for the interview guide were based in part on the issues raised in the quantitative phase of data collection, insights offered by the clinical and academic advisors, and current literature on occupational stress in nursing, medicine and psychology. Semi-structured interviews with open-ended questions were useful for delving into and exploring respondents' feelings and opinions. The questions pertained to nurses' quality of work life, location of cross-training, workload, collegial relationships, social supports and overall work environment. For example, each participant was asked to "Describe a typical shift" with follow-up probes asking them to discuss details of their shift work, their interaction with colleagues and how it was related to their quality of work life. Another question asked "What are some of the types of stress in your work setting?", and the probes included nurses to discuss stressors in different environments (work or home).

Qualitative interviews were audio recorded and be transcribed verbatim. Each respondent was given an alphanumeric code (e.g., R1, R2, etc.) to ensure confidentiality. Accuracy was ensured through a review of the audiotapes by the principal investigator. During an interview, the principal investigator restated or summarized information and then questioned the participant to determine accuracy.

\subsection{Data analysis}

The primary author transcribed and coded the themes. A thematic analysis of the semi-structured interviews was conducted. Techniques of thematic analysis, most significantly coding for content, were used with the interview data. ${ }^{[24]}$ The process was both inductive and deductive in nature and involved careful preparation of a code book, a journal for self-reflection consultations with the research team members, and, at times, recoding. ${ }^{[25]}$ The primary author carefully read and reread the data, looking for key words, patterns, trends, and ideas in the data that would assist outline the analysis, before any analyzes was performed. ${ }^{[25]}$

Analysis began with topic coding to identify all material on the topic of obstetrical nursing, cross-training and QWL and their relationships to nurses work environment. This type of coding was descriptive and provided an accurate description of the varieties of retrieved material from the nurses' interview transcripts. Next, the interviews were re-read and the topic coding became more analytic. This process was used to demonstrate and develop categories theoretically. Analytic coding allowed for the creation of categories by questioning the data bout the new ideas developing in the new subthemes and themes. Moreover, it allows for the exploration and develop new categories and concepts.

Each theme was broken down into various subthemes that were analyzed from the six transcripts. After transcription, all participants received a copy of their transcript and they were encouraged and supported to make additions for clarity as well as to correct any errors. The feedback from the participants was vital in this research in order to understand the relationship between occupational stress, cross-training and quality of work life. This inductive work and the associated findings are based on commitment to the participant's point of view. The iterative steps for this analysis included reading and re-reading the transcribed interviews. ${ }^{[26,27]}$

The analysis was extended to an interpretative analysis of 
the underlying meaning by means of the iterative process of understanding. ${ }^{27]}$ Interpretation of the text was a dialectic undertaking, shifting from understanding to explanation and from explanation to comprehension.

The interpretation process started with reading the text several times, in order to gain an understanding of the whole interview, thus gaining a preliminary understanding of stress, nurses work environment and its context and discerning the essential features of the text. ${ }^{[28]}$ Statements that correspond to a specific theme were identified and transformed into meaningful units and then coded into themes and subthemes. ${ }^{[29,30]}$ Themes and subthemes were represented visually (through the use of conceptual mapping techniques) for ease of understanding by the research consumer and broader knowledge translation and exchange activities. ${ }^{[31]}$ Nurses were asked to verify the accuracy of the transcripts. They were also provided authorial suggestions and contributions and authenticate the data's representation of their lived experienced with the phenomena of workplace stress, QWL, location of cross-training and their connections to nurses' work environment.

While initial coding was principally descriptive in nature, as the analysis process progressed, it shifted to thematic and explanatory-based coding. The transcription symbol "/" was used to indicate phrase boundaries. ${ }^{[32]}$ Capital letters were used to mark an increase in the voice tone relative to previous talk. Respondents were coded (R1, R2, R3, R4, R5 and R6). Semi-structured interview data were analyzed using NVivo (version 8.0) qualitative analysis software at Laurentian University. ${ }^{[33]}$

A narrative was developed that described the manner in which the emergent themes pertaining to the nurses' experiences with job stress may help explain the quantitative findings. As well, direct quotations from the transcripts were used in the research study to complement the aforementioned rich narrative. This strategy is grounded in a post-positive ontology wherein reality is assumed to exist but is imperfectly known because of basically flawed human intellectual mechanism and the fundamentally intractable nature of phenomena. ${ }^{[34]}$ A modified dualist/objectivist epistemology supports the idea that findings based on the interviews fit with preexisting knowledge in the literature.

The outcomes of the analysis process were five themes and one level of subthemes; the five major themes were: workplace stress, relationships with colleagues (in and out of the workplace), Quality of work life of obstetrical nurses, changes in care delivery and model of care (cross-training) and limited resources in the workplace.

\subsection{Ethics}

This study was reviewed and approved by the Laurentian University Research Ethics Board, Health Sciences North Ethics Committee, North Bay Regional Health Centre Research Ethics Board, the Joint Sault Area Hospital/Group Health Centre Research Ethics Board, and Timmins and District Hospital Research Ethics Board.

Participants were provided with a cover letter inviting participation, and an information letter explaining the study and informed consent form. Each participant completed and signed the informed consent form and returned it to the primary author. One copy was provided to the participants for their records. Nurses were informed that their participation was strictly voluntary and that they could stop at any time without explanation. Participants had the choice to answer only those questions they are comfortable answering and were assured confidentiality.

\section{Results}

Six nurses from three hospitals in northeastern Ontario participated in the second phase of the study. An overview of the participants in found in Table 1.

Table 1. Overview of respondents in the interviews

\begin{tabular}{llll}
\hline Nurse & Area of nursing practice & Geographic community & General attitude toward work environment \\
\hline Respondent 1 & Obstetrics & Sudbury & Very Positive \\
Respondent 2 & Obstetrics & Sudbury & Positive \\
Respondent 3 & Obstetrics & North Bay & Positive \\
Respondent 4 & Obstetrics & North Bay & Neutral \\
Respondent 5 & Obstetrics & Sault Ste. Marie & Neutral \\
Respondent 6 & Obstetrics & Sault Ste. Marie & Positive \\
\hline
\end{tabular}

\section{Thematic analyzes}

Using a thematic analytical approach, we searched for qualitative themes that appeared as being significant to the description of the phenomenon. ${ }^{[35]}$ The process involved the identi-

Published by Sciedu Press fication of themes through "careful reading and re-reading of the data". ${ }^{[36]}$ It is a form of pattern recognition within the data, where emerging themes became the categories for analysis. A coding process will be employed in order to cate- 
gorize the transcribed data to reveal themes common to the data. Five themes were identified: workplace stress, relationships with colleagues (in and out of the workplace), Quality of work life of obstetrical nurses, changes in care delivery and model of care (cross-training) and limited resources in the workplace (see Figure 1). The respondents interviewed were the sources of the subthemes below described through theme one to five.

The interviews were used as the basis for the themes and subthemes described below as theme. Through the use of themes and subthemes, we explored the lattice of connections between nurses QWL, location of cross-training and their work environment.

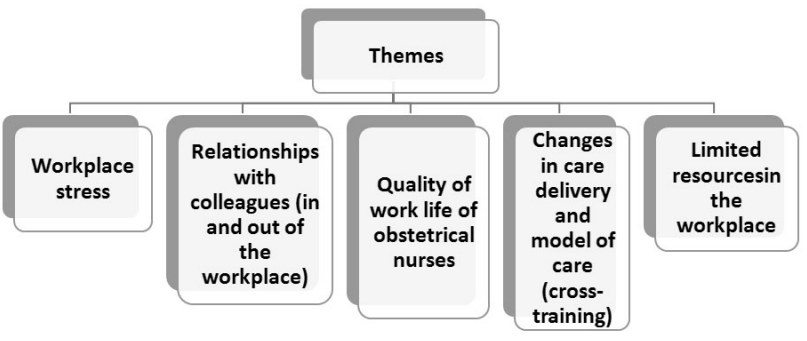

Figure 1. Thematic categories from semi-structured interviews

\section{Theme \#1 Workplace stress}

The majority of the study respondents spoke about the stressors of their work environment. These stressors included the actual work the nurses do as well as their relationships with colleagues. One respondent voice offered the following insight into the pressure she experienced from physicians and her nurse-manager:

“They [the physicians] you know/ and they'll even go to the managers who tell us 'no there's only three of them' and that's what it's supposed to be but if they buck enough the physicians and they go and talk to the manager they can't really stop them. So that's stressful like when they already know we already got three moms and you want to bring in two more inductions/ so a lot of times as soon as one delivers they'll say bring the other patient in/ It could be like eleven at night and they're still wanting to push these inductions. So that's kind of stressful." (R3)

Analyzing these subthemes provides evidence of the relationships between the themes and nurses QWL, cross-training and work environment. The first time, workplace stress identified four key subthemes (see Table 2). The first, busy work environment comprised of the ongoing demands of the clinical setting including staff shortages and new systems were key elements in the nurses' remarks about workplace stress. The voice of one nurse captured this subhtheme: “... sometimes it gets so busy that you just kind of have to go wherever the action is" (R5). The second subtheme was physical stressors that included the types of physical stressors identified included acute low back, shoulder, and neck pain. The third subtheme was mitigating stress which was the efforts are made by nurses to prevent stressful situations; examples include improving communication with colleagues, identifying where equipment is located before a shift begins, and working collaboratively. The final emotional stressors was when something goes wrong in obstetrics, the nurses identified this stress as significant given the general climate of obstetrical nursing.

Table 2. Theme one and subthemes

\begin{tabular}{llc}
\hline Subtheme and explanation & Number of Sources & References \\
\hline $\begin{array}{l}\text { Busy Work Environment: The immediate demands of the clinical setting } \\
\text { including staff shortages and new systems. }\end{array}$ & 28 \\
$\begin{array}{l}\text { Physical Stressors: The types of physical stressors identified acute low back, shoulder, and neck pain. } \\
\text { Mitigating Stress: Efforts are made by nurses to prevent stressful situations by improving }\end{array}$ & 5 \\
$\begin{array}{l}\text { communication with colleagues, identifying where equipment is located before shift begins and } \\
\text { working collaboratively. }\end{array}$ & 3 \\
$\begin{array}{l}\text { Emotional Stressors: When something goes wrong in obstetrics, it is so contrary to what normally } \\
\text { occurs that the nurses identified this stress as significant. }\end{array}$ & 24 \\
\hline
\end{tabular}

Theme \#2 Relationships with colleagues (in and out of the workplace)

Another theme discovered in the interviews was the need for relationships. While relationships can refer to the interactions between colleagues in a social setting, for nurses, relationships can also be an important part of the teamwork required to provide safe patient care. One nurse voiced the following about her relationships with colleagues and how they progressed from limited interactions to more collegial exchanges. Moreover, when the relationships were stronger, work was improved:

"Even though you know that's intimidating 
when you start a new job, you don't know people and sometimes you don't want to go to these functions by yourself but after doing that a few times I found that I got to know people better and they were even more kind of friendly towards you in the work setting which helped your work life that way." (R2)

The second theme was relationships and consisted of nine subthemes. The first subtheme was interdisciplinary and teamwork which includes teamwork and interdisciplinary interactions which were recognized as essential to care, the nurses also identified some of the inherent challenges and stressors of interdisciplinary and teamwork. A voice of one participant stated that

"We work closely with respiratory therapy, um social services so we have two social workers. And, uh uh, pharmacy technicians kind of come in and out, uh biomed we work with a lot for our equipment, if there are any equipment issues." (R3)

Management and employee relations was the second subtheme, and it linked to nurses across the three sites identified that the relationship with the unit manager was key in facilitating a positive QWL and in minimizing stress. The next subtheme was enjoyable working environment that included obstetrical nursing is generally a positive experience given its outcomes. Nurse-Nurse Relations describes the following subtheme which is about relationship between nurses was reported to be positive although respondents suggested that they could be strengthened through improved communication and training opportunities. Equally important is nurse's relationships with physicians as describe in the next subtheme physician relations. Some stressful situations were as a result of physicians bringing patients to the unit when it was already full or not communicating sufficiently with nurses about complicated deliveries. This is particularly true when there are elevated workload levels and nurses are short staffed.

The next subtheme examined new grads and mentoring. The nurses expressed concern about the lack of mentoring by some clinically experienced nurses of new graduates. This relationship needs to be developed and expanded, especially given the expanding role of cross-training in obstetrical nursing. Nurses also discussed power imbalances. Power differences among nurses, between nurses and their unit managers, and with other health care professionals (particularly with physicians) were described. Among nurses' relationships, personal relationships with colleagues were important in their work-life balance. Nurses reported having strong a relationship with their colleagues and attending social events together outside of the work environment. This was a source of pride and a higher QWL for some nurses in Table 3.

Table 3. Theme two and subthemes

\begin{tabular}{|c|c|c|}
\hline Subtheme and explanation & Number of Sources & References \\
\hline $\begin{array}{l}\text { Interdisciplinary and Teamwork: while teamwork and interdisciplinary interactions were recognized as } \\
\text { essential to care, the nurses consistently identified some of the inherent challenges and stressors. }\end{array}$ & 6 & 73 \\
\hline $\begin{array}{l}\text { Management and Employer Relations: Nurses across the three sites identified that their relationship with } \\
\text { their unit manager was key in facilitating a positive QWL and in minimizing stress. }\end{array}$ & 5 & 35 \\
\hline Enjoyable Working Environment: Obstetrical nursing is generally a positive experience given its goals. & 6 & 13 \\
\hline $\begin{array}{l}\text { Nurse-Nurse Relations: The relationship between nurses was positive although respondents suggested that } \\
\text { they could be strengthened through improved communication and training opportunities. }\end{array}$ & 6 & 32 \\
\hline $\begin{array}{l}\text { Physician Relations: Some stressful situations were as a result of physicians bringing patients to the unit } \\
\text { when it was already full or not communicating sufficiently with nurses about complicated deliveries. }\end{array}$ & 5 & 22 \\
\hline $\begin{array}{l}\text { New Grads and Mentoring: Nurses expressed their concern about the lack of mentoring by some clinically } \\
\text { experienced nurses towards new graduates. This relationship needs to be developed and expanded, } \\
\text { especially given the expanding role of cross-training in obstetrical nursing. }\end{array}$ & 5 & 13 \\
\hline $\begin{array}{l}\text { Power Imbalances: There exist power differences among nurses, between nurses and their unit managers } \\
\text { and with other health care professionals (particularly with physicians). }\end{array}$ & 4 & 13 \\
\hline $\begin{array}{l}\text { Personal Relationships with Colleagues: Nurses reported having a strong relationship with their } \\
\text { colleagues and attending social events outside of the work environment. This was a source of pride and a } \\
\text { higher QWL for some nurses. }\end{array}$ & 4 & 9 \\
\hline
\end{tabular}

\section{Theme \#3 Quality of work life of obstetrical nurses}

All respondents commented on the quality of their work lives. Given that job satisfaction and overall happiness at work were reported by the nurses, the take away is that, in general, the nurses enjoyed positive work lives. One voice reflected on her work setting in the following way:

"Well it's usually a good floor to work on, it's usually a happy environment and you get to 
share in people's like probably the best experience of their life is having their first baby, or second or third. Uhmm and you get to share in that, see how happy they are. SOMETIMES it's not always happy but that's a small percentage of the deliveries. Uhmmm and that why I guess why I enjoy working there.” (R4)

The third theme identified by nurses was quality of work life. Some nurses identified that they preferred a working environment including labor, or delivery, or post-partum. The voice of one nurse capture this subhtheme:

"I prefer working in the delivery room rather than post-partum, but that I started in the delivery room. Most people uhmm, started in postpartum, like the older girls they usually like to stay in post-partum. But, I like that whole cross trained area, that way you get to know what from beginning to end.” (R1)

Nurse perceived QWL as a comprehensive term that encapsulated both work and non-work factors. QWL for nurses was evident in the strength of their relationship with colleagues, social events, and collaborations with other health care professionals. Their definition is in line with that used in this study which defined QWL as a way of thinking about people, work, and organizations. Its distinguishing elements are a concern about the impact of work on people as well as on organizational effectiveness and the idea of participation in organizational problem solving and decision making. ${ }^{[37]}$ Recommendations for improvement was identified as improvements equipment and facilities in the unit while others stressed more opportunities for training and education. Enjoyable Working Environment was also a subtheme reported. Generally, the work environment was a positive space that allowed nurses to develop and build meaningful relationships and maintain their clinical skills (see Table 4).

Table 4. Theme three and subthemes

\begin{tabular}{lll}
\hline Subtheme and explanation & Number of Sources & References \\
\hline $\begin{array}{l}\text { Preference of Working Area: Some nurses identified they had a preferred working environment } \\
\text { including either labor delivery or post-partum. }\end{array}$ & 5 \\
$\begin{array}{l}\text { Nurse Perceived QWL: QWL for nurses was defined by responses by the strength of their relationship } \\
\text { with colleagues, social events and collaborations with other health care professionals. }\end{array}$ & 6 \\
$\begin{array}{l}\text { Recommendations for Improvement: Some recommended providing greater financial resources to } \\
\text { improve equipment and facilities in the unit while others stressed providing more opportunities for } \\
\text { training and education. }\end{array}$ & 3 \\
$\begin{array}{l}\text { Enjoyable Working Environment: Generally, the work environment was a positive space that allowed } \\
\text { for nurses to develop and build meaningful relationships and to uphold their clinical skills. }\end{array}$ & 6 \\
$\begin{array}{l}\text { Unpredictability of occupation: Labor can occur at any time: The unpredictability of the work } \\
\text { environment was a source of stress for nurses. }\end{array}$ & 5 \\
$\begin{array}{l}\text { Recognition and Appreciation: Nurses identified that their QWL would be improved if they were } \\
\text { recognized for their efforts in the unit. There was an emphasis that management should recognize their } \\
\text { efforts through verbal acknowledgement. }\end{array}$ & 3 \\
\hline
\end{tabular}

Theme \#4 Changes in care delivery and model of care (Location of cross-training)

The majority of the nurses said that location of cross-training was beneficial and that it helped increase clinical competency. In this study, the term cross training refers to being competent to provide care in all aspects of obstetric care. The voice of one of the respondents in the passage below presents one instance through which clinical competence was augmented:

"Um I don't know necessarily which AREA of cross-training was more challenging, I mean learning how to take care of a lady in labor and as she's delivering a baby I found you know stressful and challenging at first because it was completely new to me. But, it was never to the point that I, I didn't enjoy it, I still, I enjoyed it even during the training part." (R1)

Thus, although there are stressors when cross training is involved, such as the above reference to the work of the nurse at the birth of a new baby, there is also recognition that cross training leads to new skills and even enjoyment. The fourth theme, changes in care delivery and model of care (location of cross-training), is tied intimately to cross-training. As discussed previously, cross-training has both positive implications on nurses' ability to learn new skills and increase their clinical competencies but also negative implications through elevated work stress. The first subtheme related to the model of care or the cross-training shifted the level of care as nurses can work with one patient across all areas. One nurse stated: 
"I felt pretty comfortable because we do, we did the delivery room side so we actually did the delivery room and the recovery period and then we would transfer them to post-partum. So basically we do a lot of the breast feeding in the recovery, if they usually hemorrhage it's going to be in the recovery period, not always but we kind of knew what to do so." (R6)

Studies showing high stress levels may be as a result of Lack of functioning equipment. Some nurses identified that looking for equipment took up a great deal of their time. The voice of one nurse describes this challenge:

"They only gave us thirteen post-partum beds we left from the hospital with 17 beds so, our overflow of patients has to go to Peds, and we try to give them like post-partum moms of like uhh one day that are going to be going home within the next day or two." (R3)

It also acted as a barrier in training student nurses and in providing care to families. Period of Transition was also identified as theme. This is the period during which nurses begin cross-training. According to the nurses, it includes feelings of apprehension, stress and anxiety. Some nurses also commented on positive experiences including learning new skills and becoming proficient in all areas of obstetrical nursing.

Drawbacks of cross-training was a subtheme that some clinically experienced nurses who had worked in one area (e.g., labor, delivery and post-partum) of obstetrics left their jobs. As an outcome, new graduates and inexperienced nurses had fewer mentors to foster their clinical training. Nurses Disliking Cross Training was identified as subtheme. Comparison with American-based Care was also made by one respondent. The nurse had worked in both the Canadian and American health care systems.

Increased responsibilities and maintaining competencies was identified as another consequence of cross-training and as a source of stress. As a result of cross-training, nurses have, higher stress levels and greater accountability to the College of Nurses of Ontario, and to families. Some felt more continuing education opportunities in rural and northern communities were warranted. Relevant to northern and rural settings, challenges of small northern hospitals was identified as another subtheme. Scope of practice was another subtheme that has implications in broadening nurses' clinical skills was noted in the interviews. In turn, their increased scope of practice brings more responsibility and accountability to their regulatory body and can be a source of increased occupational mental and physical stress (see Table 5).

Table 5. Theme four and subthemes

\begin{tabular}{|c|c|c|}
\hline Subtheme and explanation & Number of Sources & References \\
\hline Model of Care: It has shifted the level of care as nurses can work with one patient across all areas. & 6 & 52 \\
\hline $\begin{array}{l}\text { Resources: Lack of functioning equipment: Some nurses identified that looking for equipment took up a } \\
\text { great deal of their time. It also acted as a barrier in training student nurses and in providing care to families } \\
\text { in obstetrics. }\end{array}$ & 6 & 43 \\
\hline $\begin{array}{l}\text { Period of Transition: This is the period where nurses first begin with cross-training and includes feelings } \\
\text { of apprehension, stress and anxiety. Some nurses also stated positive experiences including learning new } \\
\text { skills and becoming proficient in all areas of obstetrical nursing. }\end{array}$ & 6 & 33 \\
\hline $\begin{array}{l}\text { Drawbacks of Cross-Training: Clinically experienced nurses that worked in one area (e.g., labor, delivery } \\
\text { and post-partum) of obstetrics left their jobs. New graduates and inexperienced nurses had fewer mentors } \\
\text { to foster their clinical training. }\end{array}$ & 5 & 30 \\
\hline $\begin{array}{l}\text { Nurses Disliking Cross Training: Respondents indicated that cross-training was a source of stress and also } \\
\text { increased their professional clinical responsibility to the CNO. }\end{array}$ & 4 & 19 \\
\hline $\begin{array}{l}\text { Comparison of US- Based Care: One nurses worked in both the Canadian and American health care } \\
\text { systems. She reported that the American system had implemented cross-training many years ago in her } \\
\text { hospital with a higher level of organization. The Canadian transition towards cross-training was } \\
\text { disorganized. }\end{array}$ & 2 & 16 \\
\hline $\begin{array}{l}\text { Increased responsibilities and Maintaining Competencies: As a result of cross-training, nurses have } \\
\text { greater accountability to the CNO and also to their families. Some felt more continuing education } \\
\text { opportunities in rural and northern communities were warranted. }\end{array}$ & 2 & 14 \\
\hline $\begin{array}{l}\text { Northern Challenges of Small Hospitals: There is a health human resources shortage of nurses. Also, } \\
\text { nurses identified having more local training and education opportunities so they would not have to travel } \\
\text { to Southern Ontario. }\end{array}$ & 2 & 9 \\
\hline Scope of Practice: Cross training as broaden nurses clinical skills. & 3 & 5 \\
\hline
\end{tabular}




\section{Theme \#5 Limited resources in the workplace}

In order to be experts in the provision of safe patient care for new mothers and their infants, the nurses recognize their need to keep up their skills and to develop new ones. The following quotation reveals one nurse's concern about the limited resources in accessing education and the personal costs she has incurred in order to get the training she needs:

"Well in my current role if I speak about my stressors, um it's a, it's a stressor of mine to um, uh, to be creative enough to uh, uhm access uh educational funds um from a college point of view. So I've paid, self-paid many um workshops and in-services because I knew that it wasn't going to be funded. And yet I don't feel like I can access the bursary at the hospital, not putting in enough hours um. So, I probably struggle more than they do, that's kind of ironic because I work in an educational institution but I struggle more than they do for funds." (R5)

The fifth theme was limited resources related to the nurses working profile. Nurses working across the three hospitals identified typical shift as a subtheme. The typical shift was described as being eight or 12 hours in length with a 30 minute break. The voice of one respondent describes their shift work:

\begin{abstract}
"And one uh, we uh, we find that uh our assignments I'm not quite sure how you'd classify that, but they're by um areas, so one nurse would be assigned triage uh area and she would also um, she would also go in to the operating suite if there is a caesarean section. So it's like a triage slash um c-section and then one uh nurse is assigned to labour and delivery and uh, one or two nurses are assigned to post-partum um, depending on the um, the um patient um, uh census uh that shifts a little bit." (R2)
\end{abstract}

Career advancement and training was identified by nurses that they needed employer support both in terms of financial incentives and educational opportunities in order to keep their clinical skills relevant. One nurse articulated the issues surrounding this subtheme:

“... there's kind of nowhere else to go in terms of vertical opportunities are limited, I can't say that I know that for a fact I'm not in that um position um. I know that our manager is very supportive of uh, of um, staff um, being in education roles, so we have um three uh part time um nurses that also do clinical um instructing uh for the school of nursing and she uh is very supportive of blocking those two or three days a week that they need to uh, that they need to be supported to conduct uh those roles. Um they're they also have uh a good um, probably better than what I see, what I experience in the school of nursing they have better bursaries, um they have access to bursaries for things link uh um CNA certification, any course work that they do towards their $\mathrm{BScN}$ or their Masters um or any conferences they attend is paid. Well in my current role if I speak about my stressors, um it's a, it's a stressor of mine to um, uh, to be creative enough to uh, uhm access uh educational funds um from a college point of view. So I've paid, self paid many um workshops and in-services because I knew that it wasn't going to be funded. And yet I don't feel like I can access the bursary at the hospital, not putting in enough hours um. So, I probably struggle more than they do, that kind of ironic because I work in an educational institution but I struggle more than they do for funds." (R4)

Many felt that they were left on their own for their continuing education and development. Support was identified as another subtheme. Generally, there are good support systems available to obstetrical nurses but, in certain areas including lack of resources and communication, there are breakdowns. Financial restrictions was also a subtheme that nurses reported. Nurses stated that working in a financially austere environment meant inadequate resources such as malfunctioning or broken equipment and a lack of nursing staff. The lack of education and training was emphasized as the lack of continuing professional development and training for nurses. There was a high rate of staff turnover with the implementation of cross-training at some hospital sites. Some felt that nurses had to take more time off of work in terms of sick days because of the physical and mental demands of the workplace (see Table 6).

\section{Discussion}

The qualitative interviews explored and provided a richer understanding of the work environment of registered nurses working in obstetrics at four hospitals in northeastern Ontario, Canada. In particular, five key themes emerged: workplace stress, relationships with colleagues (in and out of the workplace), Quality of work life of obstetrical nurses, changes in care delivery and model of care (cross-training) and limited resources in the workplace. 
Table 6. Theme five and subthemes

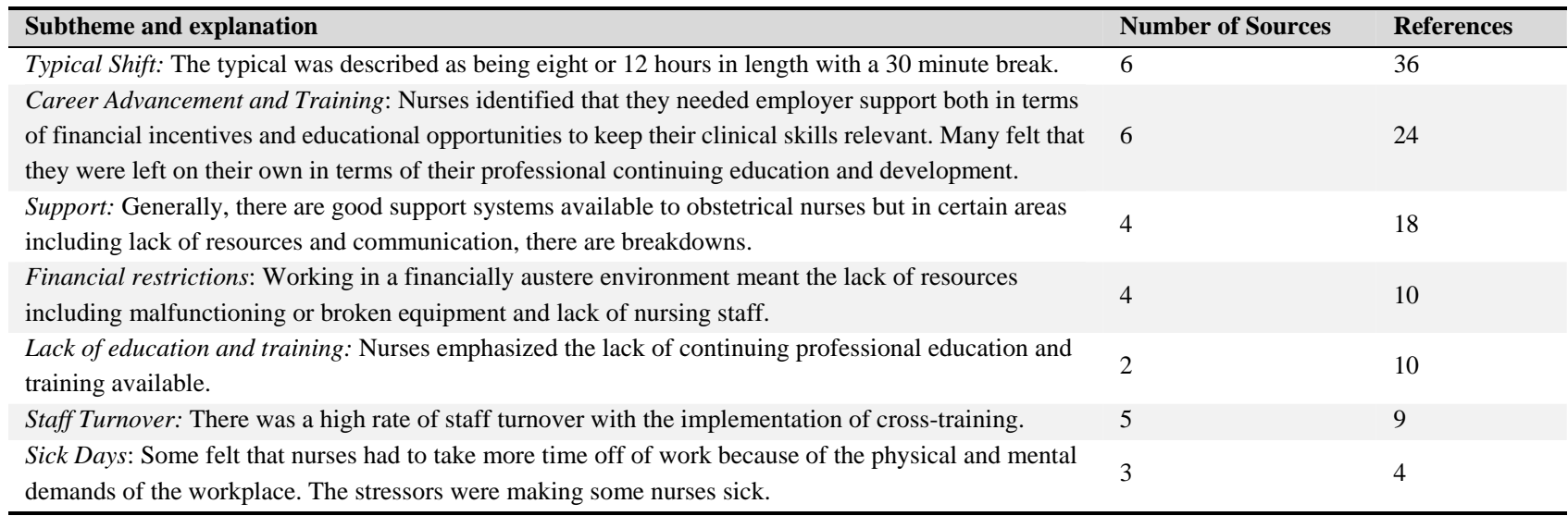

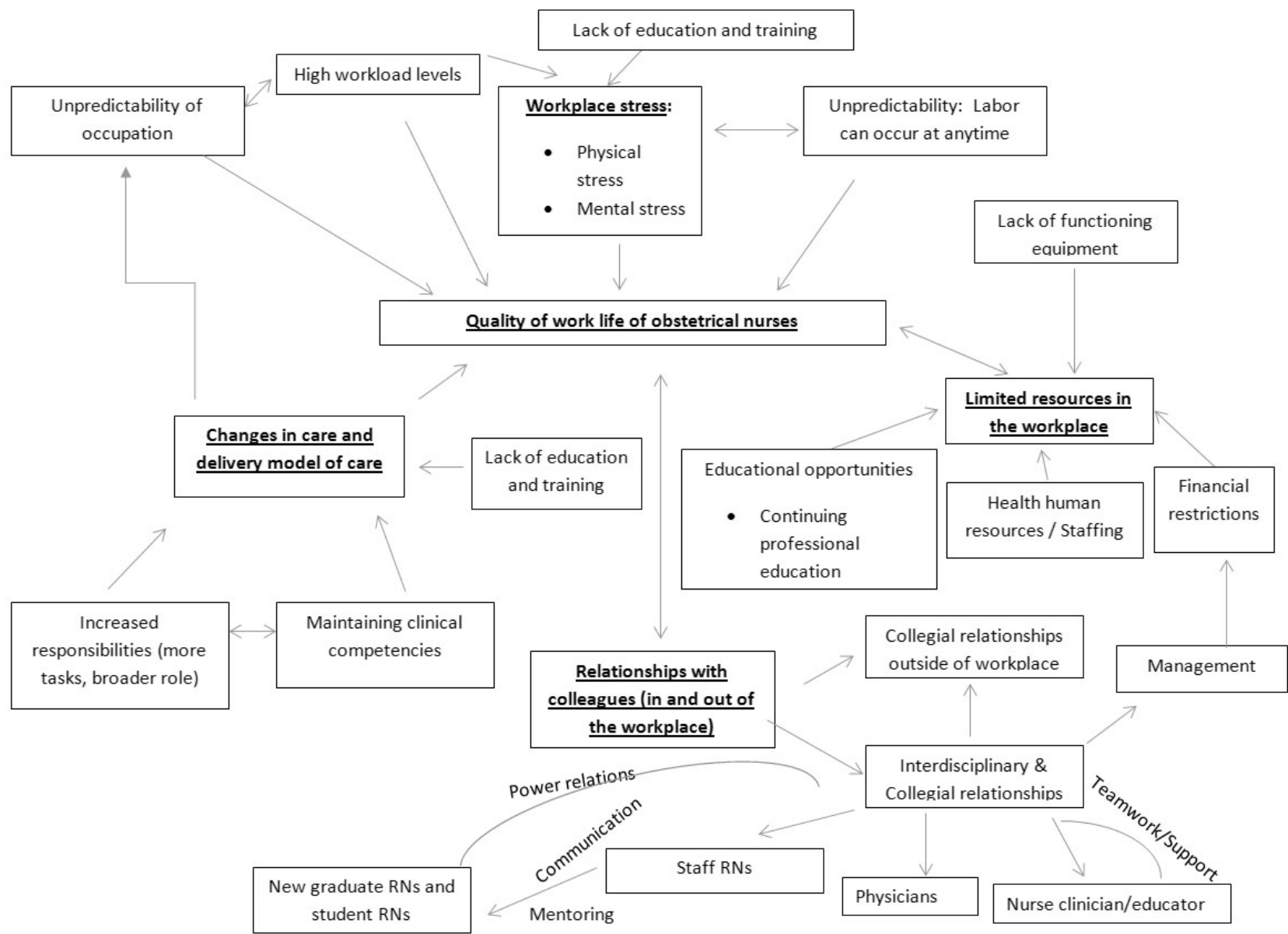

Figure 2. Conceptual map of themes and subthemes references

Work stress was identified as a theme and has been linked to a lack of staffing among nurses. ${ }^{[38]}$ However, the work environment was a positive space that allowed nurses to develop and build meaningful relationships and maintain their clinical skills. This is finding is unique as many studies report of a nursing environment that is laden with physical and mental stress, ${ }^{[39,40]}$ high workloads, ${ }^{[41]}$ burnout ${ }^{[42]}$ and job dissatisfaction. ${ }^{[43,44]}$ These findings are presented in a conceptual map to demonstrate the relationship of the themes with the subthemes (see Figure 2). The map allows for a visual representation of the multifactorial and complex themes and subthemes that constitutes obstetrical nurses work envi- 
ronments.

One of the important themes discussed by participants was that the Changes in care delivery and model of care. Supporting the research by Inman et al. ${ }^{[45]}$ drawbacks of crosstraining was a subtheme that some clinically experienced nurses who had worked in one area (e.g., labor, delivery and post-partum) of obstetrics left their jobs. As an outcome, new graduates and inexperienced nurses had fewer mentors to foster their clinical training. Nurses' dislike of cross-training was identified as subtheme as well. In examining work sharing in factory assembly lines, Schultz and colleagues (2003) cautioned that the behavioral effects of cross-training can reduce or even eliminate its potential benefits. ${ }^{[46]}$ Similarly, some of the nurses indicated that cross-training was a source of stress and increased their professional clinical responsibility to the College of Nurses of Ontario (regulatory body in the province of Ontario, Canada). Indeed, given the already elevated workloads ${ }^{[47]}$ that nurses experience, cross-training may place an additional burden on nurses' health and wellbeing.

There was a high rate of staff turnover with the implementation of cross-training at some hospital sites. Some of the nurses felt that they had to take more time off work as sick days because of the physical and mental demands of the workplace. The stressors of the workplace made some nurses sick; this is supported by numerous studies ${ }^{[48,49]}$ and has severe consequences on health and well-being.

Limited resources as identified as a theme by the participants. Subthemes included typical shifts, career advancement and training, support, and financial restrictions. The typical shift was described as being eight or 12 hours in length with a 30minute break. Studies have shown that increased educational and work opportunities promote a healthy work environment for nurses and increases their work ability. ${ }^{[39]}$ Career advancement and training were also identified by the nurses; both financial incentives and educational opportunities are necessary to keep their clinical skills relevant. Many felt that they were left on their own for their continuing education and development.

Nurses perceived QWL as a comprehensive term that encapsulated both work and non-work factors. QWL for nurses was evident in the strength of their relationship with colleagues, social events, and collaborations with other health care professionals. This sense of QWL is in line with that used in this study, which defines QWL as a way of thinking about people, work, and organizations. Its distinguishing elements are a concern about the impact of work on people as well as on organizational effectiveness and the idea of participation in organizational problem solving and decision making. ${ }^{[37]}$ Recommendations for improvement pertained to improvements in equipment and facilities in the unit as well as more opportunities for training and education. Enjoyable working environment was a further subtheme. Generally, the work environment was a positive space that allowed nurses to develop and build meaningful relationships and maintain their clinical skills.

From the interviews, we found that location of cross-training had both positive and negative ramifications of QWL. It is important to state that the interviews served to explain and provide greater depth to understanding the work environment of obstetrical nurses, in particular how changes in the delivery of care impacted not only nurses workloads, relationships but also their work stressors. Some of the participants identified that looking for equipment took up a great deal of their time and efforts during cross-training. It also acted as a barrier in training student nurses and in providing care to families. Others stated that during the period of transition, in which nurses begin cross-training, there were feelings of apprehension, stress and anxiety. The negative implications of cross-training may be mitigated through skillful management. Many of the potentially negative impacts stem from thoughtless implementations of cross-training. ${ }^{[46]}$ At the hospital where cross-training occurred (Sudbury, Ontario, Canada), there was a high rate of staff turnover with the implementation of cross-training at some hospital sites. Some felt that nurses had to take more time off of work in terms of sick days because of the physical and mental demands of the workplace. The stressors were making some nurses sick which is supported by numerous studies ${ }^{[48,50]}$ and has severe consequences on their health and well-being. However, if managed strategically and with care, cross-training should provide a net benefit for patients, their families, nurses, and employers. ${ }^{[46]}$

\section{Trustworthiness of the study and findings}

Rigour was ensured in three ways. The first involved the use of member checking after each interview. After a transcription was completed, the participant received a copy of the transcript by e-mail and was invited to make additions and/or changes for clarity and accuracy. Comments were returned either by email or phone. This feedback from the participants was vital to understanding the relationships between occupational stress, location of cross-training, and QWL. Member checking is a recognized means of error reduction. ${ }^{[51]}$

The primary author also consulted with other members of the research team prior to and during the analysis process. Agreement on the overall analysis strategy, coding categories, and the principal themes represent important commitment to the integrity of the study. 
Data collection and analysis were reflexive and iterative in nature. Being explicit and as self-aware as possible about personal assumptions, values and biases, and how they may come into play during the study contributed to the study's confirmability. ${ }^{[31]}$ Clarity in the author's role coupled with data checks (e.g., for bias, deceit, informant knowledgeability, etc.) contributed to the study's reliability. ${ }^{[31]}$

Although we purposefully selected nurses who were able to describe experiences in the obstetrical units in northeastern Ontario, these participants were self-selected by volunteering to take part in the study. This initial sample of nurses may bias the findings, as those with more vibrant or potent experiences may have been compelled to participate, while our study missed those who left their workplaces due to unfavorable working conditions. Those nurses who did not take part in the interviews may have other important characteristics and attributes that we did not identify. Finally, the quality of the analysis is influenced by the quality of the data. We explored sensitive topics pertaining to nurses work environments and therefore the degree of vulnerability felt and risk in sharing is related to the rapport the investigators were able to make with the participants in person and over the phone.

\section{Conclusions}

The present study highlights both the positive and negative aspects of obstetrical nurses work environments in northeastern Ontario. The respondents are highly resilient individuals that handle demanding workloads coupled with limited resources in providing patient care in a stressful obstetrical care work environment. Given the shortage of healthcare professionals in rural communities remains a serious challenge to equitable healthcare delivery. In Canada, the nursing shortage and high turnover rate of nurses are expected to worsen over the next ten years, making recruitment and retention of nurses a priority for health care. Therefore, creating and maintaining a vibrant, healthy and safe work environment for nurses is of great importance.

\section{ACKNOWLEDGEMENTS}

We would like to thank Dr. Robert Schinke for his contribution and productive discussions regarding this work.

\section{Conflicts of InTERest Disclosure}

The authors declare that there is no conflict of interest statement.

\section{REFERENCES}

[1] Kath LM, et al. Predictors of nurse manager stress: a dominance analysis of potential work environment stressors. International Journal of Nursing Studies. 2013; 50(11): 1474-1480. PMid:23522937 http://dx.doi.org/10.1016/j.ijnurstu.2013.02.011

[2] Hayes B, Douglas C, Bonner A. Work environment, job satisfaction, stress and burnout among haemodialysis nurses. Journal of Nursing Management. 2013. PMid:24372699 http://dx.doi.org/10.11 $11 /$ jonm. 12184

[3] Canadian Institute for Health Information. 2005 National Survey of the Work and Health of Nurses. Health Canada: Ottawa, ON; 2005.

[4] Beck CT, Gable RK. A mixed methods study of secondary traumatic stress in labor and delivery nurses. Journal of Obstetric, Gynecologic \& Neonatal Nursing. 2012; 41(6): 747-760. PMid:22788967 http://dx.doi.org/10.1111/j.1552-6909.2012.01386.x

[5] Lightfoot $\mathrm{N}$, et al. Challenges and rewards of health research in northern, rural, and remote communities. Annals of Epidemiology. 2008; 18(6): 507-514. PMid:18261925 http://dx.doi.org/10.1016 /j.annepidem.2007.11.016

[6] Makin AM, Winder C. A new conceptual framework to improve the application of occupational health and safety management systems. Safety Science. 2008; 46(6): 935-948. http://dx.doi.org/10. 1016/j.ssci.2007.11.011

[7] Djukic M, et al. Work environment factors other than staffing associated with nurses' ratings of patient care quality. Health Care Management Review. 2013; 38(2): 105-114. PMid:22067427 http: //dx.doi.org/10.1097/HMR.0b013e3182388cc3

[8] Canadian Nurses Association. Health Human Resources. 2012. Available from: http://www2.cna-aiic.ca/CNA/issues/hhr/de fault_e.aspx

Published by Sciedu Press
[9] Buerhaus PI, Auerbach DI, Staiger DO. The recent surge in nurse employment: Causes and implications. Health Affairs. 2009; 28(4): w657-w668. PMid:19525286 http://dx.doi .org/10.1377/hlt haff. 28.4.w657

[10] Requena F. Social Capital, Satisfaction and Quality of Life in the Workplace. Social Indicators Research. 2003; 61(3): 331-360. http://dx.doi.org/10.1023/A:1021923520951

[11] Morschhäuser M, Sochert R. Healthy work in an ageing Europe Federal Association of Company Health Insurance Funds, Essen, Germany. 2006; 76.

[12] Akdere M. Improving quality of work-life: Implications for human resources. The Business Review. 2006; 6(1): 173-177.

[13] Vagharseyyedin SA, Vanaki Z, Mohammadi E. The nature nursing quality of work life: an integrative review of literature. Western Journal of Nursing Research. 2010. http://dx.doi .org/10.1177/0 193945910378855

[14] Nowrouzi B, et al. The relationship between Quality of Work Life And Location of Cross-Training Among Obstetric Nurses In Urban Northeastern Ontario, Canada: A Population-Based Cross Sectional Study. International Journal of Occupational Medicine and Environmental Health. 2015; 28(3).

[15] Macik-Frey M. Advances in Occupational Health: From a Stressful Beginning to a Positive Future. Journal of Management. 2007; 33(6): 809-840. http://dx.doi.org/10.1177/0149206307307634

[16] Killian JG. Career and technical education teacher burnout: impact of humor-coping style and job-related stress. Southern Illinois University: Carbondale. 2004.

[17] Van Laar D, Edwards JA, Easton S. The Work-Related Quality of Life scale for healthcare workers. Journal of Advanced Nursing. 2007; 
60(3): 325-333. PMid:17908128 http://dx.doi.org/10.1111 /j.1365-2648.2007.04409.x

[18] Mustajbegović J. Workplace Hazards Workplace hazards. Encyclopedia of Public Health. 2008; 1467-1469.

[19] Rajala HK, Väyrynen S. Constructing "core stories” for contributing practical safety actions in industrial units. Safety science. 2010; 48(10): 1393-1401. http://dx.doi.org/10.1016/j.ssci.20 10.05 .014

[20] Spreitzer G. Psychological empowerment in the workplace: dimensions, measurement, and validation. Academy of Management Journal. 1995; 38(5): 1442-1462. http://dx.doi.org/10.2307/256 865

[21] Pino O, Rossini G. Perceived Organizational Stressors and Interpersonal Relationships as Predictors of Job Satisfaction and Well-Being among Hospital Nurses. International Journal of Psychology and Behavioral Sciences. 2012; 2(6): 196-207. http://dx.doi.org/1 $0.5923 /$ j.ijpbs. 20120206.02

[22] Elsler D. Exchange of Economic Incentives Good Practice at European Level. Research on the effectiveness of prevention measures at the workplace. 2009.

[23] Creswell JW. Research design: Qualitative, quantitative, and mixed methods approaches. 2013: Sage Publications, Incorporated.

[24] Guest G, Mac Queen KM, Namey EE. Applied thematic analysis. Los Angeles, CA: Sage; 2012. http://dx.doi .org/10.4135/9 781483384436

[25] Burns B, Grove SK. The practice of nursing research: Conduct, critique, and utilization. St. Louis, Missouri: Elsevier; 2005.

[26] Creswell JW. Research Design: Qualitative, Quantitative, and Mixed Methods Approaches. Sage Publications, Inc. 2008.

[27] Richards L, Morse JM. Readme first for a user's guide to qualitative methods. Sage; 2012.

[28] Severinsson E. Moral stress and burnout: Qualitative content analysis. Nursing and Health Sciences. 2003; 5(1): 59-66. http://dx.doi .org/10.1046/j.1442-2018.2003.00135.x

[29] Ricoeur P. Interpretation Theory: Discourse and the Surplus of Meaning. Forth Worth, Texas: Christian University Press; 1976.

[30] Ricoeur P. Hermeneutic and Human Sciences. Cambridge: Cambridge University Press; 1981.

[31] Miles MB, Huberman AM. Qualitative Data Analysis: An Expanded Sourcebook. Thousand Oaks: Sage Publications; 1994; 338.

[32] Bailey PH, Tilley S. Storytelling and the interpretation of meaning in qualitative research. Journal of Advanced Nursing. 2002; 38(6): 574-583. PMid:12067396 http: //dx.doi.org/10.1046/j. 136 5-2648.2000.02224. $\mathrm{x}$

[33] QSR. N'Vivo Version 8 for Windows. QSR International Pty Ltd: Doncaster, Australia. 2007.

[34] Denzin NK, Lincoln YS. Handbook of Qualitative Research. Thousand Oaks, CA: Sage Publications; 1994. PMid:7600288

[35] Daly J, Kellehear A, Gliksman M. The public health researcher: A methodological approach. Melbourne, Australia: Oxford University Press; 1997.

[36] Rice B, Snyder A. Reconciliation in the context of a settler society: Healing the legacy of colonialism in Canada, M.B. Castellano, L. Archibald, and M. DeGagné, Editors. Aboriginal Healing Foundation: Ottawa, Canada. 2008; 43-63.

[37] Nadler DA, Lawler EE. Quality of work life: Perceptions and direction. Organizational Dynamics. 1983; 11(3): 20-30. http: //dx.doi.org/10.1016/0090-2616(83)90003-7
[38] Mealer M, Jones J, Moss M. A qualitative study of resilience and posttraumatic stress disorder in United States ICU nurses. Intensive Care Medicine. 2012; 38(9): 1445-1451. PMid:22618093 http://dx.doi.org/10.1007/s00134-012-2600-6

[39] Golubic R, et al. Work-related stress, education and work ability among hospital nurses. Journal of Advanced Nursing. 2009; 65: 2056-2066. PMid:19627386 http://dx.doi.org/10.1111/j.1 365-2648.2009.05057 . $\mathrm{x}$

[40] Virtanen P, et al. Work stress and health in primary health care physicians and hospital physicians. Occupational and Environmental Medicine. 2008; 65(5): 364-366. PMid:18045846 http://dx . doi .org/10.1136/oem. 2007.034793

[41] Aiken L, Rafferty AM, Sermeus W. Caring nurses hit by a quality storm: Low investment and excessive workloads, not uncaring attitudes, are damaging the image of NHS trusts, argue the authors of groundbreaking research into Europe's nurse workforce. Nursing Standard. 2014; 28(35): 22-25. PMid:24779821 http: //dx.doi.org/10.7748/ns2014.04.28.35.22.s26

[42] Jourdain G, Chênevert D. Job demands-resources, burnout and intention to leave the nursing profession: A questionnaire survey. International Journal of Nursing Studies. 2010; 47(6): 709722. PMid:20138278 http://dx.doi.org/10.1016/j.ijnurst u. 2009.11.007

[43] Saber DA. Frontline registered nurse job satisfaction and predictors over three decades: A meta-analysis from 1980 to 2009. Nursing Outlook. 2014. PMid:25015408 http://dx.doi.org/10.1016/j .outlook. 2014.05.004

[44] Moore GA, Dienemann JA. Job satisfaction and career development of men in nursing. Journal of Nursing Education and Practice. 2014; 4(3): 86-93. http://dx.doi .org/10.5430/jnep.v4n3p86

[45] Inman RR, Blumenfeld DE. Assembly line team sizing with absenteeism. International Journal of Production Research. 2010; 48(22): 6537-6558. http://dx.doi.org/10.1080/002075409 03067169

[46] Schultz KL, McClain JO, Thomas LJ. Overcoming the dark side of worker flexibility. Journal of Operations Management. 2003; 21(1): 81-92. http://dx.doi.org/10.1016/S0272-6963(02 ) 00040-2

[47] Opie T, et al. Levels of occupational stress in the remote area nursing workforce. The Australian Journal of Rural Health. 2010; 18(6): 235-241. PMid:21114700 http://dx.doi.org/10.1111/j.144 0-1584.2010.01161.x

[48] Berland A, Natvig GK, Gundersen D. Patient safety and job-related stress: a focus group study. Intensive \& Critical Care Nursing: The Official Journal of the British Association of Critical Care Nurses. 2008; 24(2): 90-97. PMid:18096388 http://dx.doi .org/10.10 16/j.iccn.2007.11.001

[49] Mark G, Smith A. Occupational stress, job characteristics, coping, and the mental health of nurses. British journal of Health Psychology. 2012; 17(3): 505-521. PMid:22107162 http://dx.doi.org/10. 1111/j.2044-8287.2011.02051.x

[50] Stordeur S, D'Hoore W. Organizational configuration of hospitals succeeding in attracting and retaining nurses. Journal of Advanced Nursing. 2007; 57(1): 45-58. PMid:17184373 http://dx.doi.o $\mathrm{rg} / 10.1111 / \mathrm{j} .1365-2648.2006 .04095 . \mathrm{x}$

[51] Mays N, Pope C. Assessing quality in qualitative research. BMJ: British Medical Journal. 2000; 320(7226): 50-52. PMid:10617534 http://dx.doi.org/10.1136/bmj.320.7226.50 